\title{
Building without melting: a short review of friction-based additive manufacturing techniques
}

\author{
Sivanesh Palanivel and Rajiv S. Mishra* \\ Advanced Materials and Manufacturing Processes Institute, \\ Department of Materials Science and Engineering, \\ University of North Texas, \\ Denton, TX 76203, USA \\ Email: SivaneshPalanivel@my.unt.edu \\ Email: rajiv.mishra@unt.edu \\ *Corresponding author
}

\begin{abstract}
Fusion additive technologies have pushed the boundaries beyond what was previously envisaged in the metal community. Championed by laser-based and electron beam technologies, metal additive manufacturing has captivated the interests of aerospace, defence, energy, automotive, and medical sectors. Though game-changing, these fusion-based techniques suffer from solidification related issues which play a critical role in applications where high premium is placed on materials' performance. Furthermore, only limited number of alloys can be built due to complexities associated with melting. To address these drawbacks, parallel work on solid state technologies was initiated in the last decade. An outcome of these efforts has been the development of additive manufacturing technologies based on friction which has now reached a stage where compilation is possible. In this article, fundamental principle and features of these friction-based additive technologies are reviewed with special emphasis on their individual advantages and differences between them. In addition, further scope, challenges and potential of these technologies are highlighted.
\end{abstract}

Keywords: fusion additive technologies; metal additive manufacturing; solid state; friction-based additive manufacturing; FBAM; material performance.

Reference to this paper should be made as follows: Palanivel, S. and Mishra, R.S. (2017) 'Building without melting: a short review of friction-based additive manufacturing techniques', Int. J. Additive and Subtractive Materials Manufacturing, Vol. 1, No. 1, pp.82-103.

Biographical notes: Sivanesh Palanivel is a Technical Fellow at the Advanced Materials Manufacturing and Processing Institute (AMMPI) and a Graduate Research Assistant in pursuit of his Doctoral degree at the University of North Texas. He is a gold medallist from National Institute of Technology-Raipur, India where he received his Bachelors of Technology in Metallurgical Engineering. After undergraduate studies, he joined the Center for Friction Stir Processing and works with Dr. Rajiv Mishra. His research interests include additive manufacturing, physical metallurgy of $\mathrm{Al}$ and $\mathrm{Mg}$ alloys, alloy design using Calphad approach and field effects on microstructure. In the field of additive manufacturing, he has the first few publications on friction stir additive manufacturing and has also published on fusion additive manufacturing linking site dependent properties to microstructure. 
Rajiv S. Mishra ( $\mathrm{PhD}$ in Metallurgy from University of Sheffield) is a Distinguished Research Professor at University of North Texas from September 2011. Before that, he served as Curators' Professor of Metallurgical Engineering in the Department of Materials Science and Engineering at the Missouri S\&T. He is also the UNT Site Director of the NSF I/UCRC for Center for Friction Stir Processing (CFSP), Director of Advanced Materials and Manufacturing Processes at UNT and a Fellow of ASM International. He authored or co-authored 275 papers in peer-reviewed journals and proceedings and is principal inventor of four US patents. His current publication-based h-index is 44 and his papers have been cited more than 8,800 times. He serves on the editorial board of Science and Technology of Welding and Joining, and Materials Science and Engineering A.

\section{Introduction}

'3D printing is an enabler'. This optimistic tone and belief in the aerospace and defence industry has propelled the field ever since it started experimentation with additive manufacturing (AM) in 1988 (Koykendall et al., 2014). Since its origin, over the past 25 years, AM has started to facilitate a paradigm shift from traditional manufacturing methods by reinventing the basics of product fabrication. Such a transition has revolutionised manufacturing and expanded the envelope to several niche applications in industries ranging from medicine and electronics to transportation.

Within the transportation fleet alone, seven AM applications have significantly increased contributing to $29.6 \%$ of the total AM market volume share of US\$ 3.1 billion (DOE Report, 2015). Wohlers report puts the AM products and services at US\$ 5.1 billion (Wohlers Report, 2016). These contributions arise from applications related to concept modelling and prototyping, fabrication of low volume complex parts and replacement components using the AM technologies (Deloitte University Press, 2014; Gausemeier, 2011). Among several economic advantages; the key factor driving the interest of the aerospace industries towards AM is the ability to produce light-weight structures. The aforementioned statement can be appreciated by considering the following estimate where reducing 1 pound on each plane in a fleet of 600 aircrafts can save 11,000 gallons of fuel annually (Lyons, 2015). Although, transportation industries contribute to the lion's share of AM revenue, when compared with the overall world market volume of $\$ 706$ billion and $\$ 2$ trillion of aerospace and automobile industries, the current AM market share from these industries is marginal (Deloitte University Press, 2014; Giffi et al., 2014).

Holding to the example of transportation industry, there are three primary reasons for the subdued role of AM in this sector. These are:

1 inability to produce high performing structures (Palanivel et al. 2015a)

2 cost of the powder feedstock

3 limited number of alloys that can be built.

Though, Arcam-based electron beam melting (EBM) and EOS-based direct metal laser sintering systems (DMLS) (Vayre et al., 2012) have enabled pivotal breakthroughs in the 
field of AM, fabrication of high performance parts is limited due to solidification defects and undesirable interplay between multiple thermal cycles and evolving microstructure.

In this context, over the last few years, a number of friction-based techniques have been developed, modified and studied for their viability as AM technology. Due to their operation within the solid state, friction-based additive manufacturing (FBAM) processes possess certain advantages over conventional AM techniques, a few of which are: absence of porosity/defects in the finished part, a good balance of mechanical properties, and low level of residual stresses. After being conceived as a possible route for AM by White in his patent in 2002 (White, 2002), FBAM technologies have now reached a point where documentation of the developments within this field is possible. Furthermore, unlike fusion-based AM technologies, to the best of the authors' knowledge, no review on friction-based additive technologies exist. Therefore, the objective of this review is to:

1 summarise the innovations that took place relating to FBAM

2 catalogue advantages and limitations of individual FBAM techniques

3 identify the current and potential applications of these technologies.

\section{Friction-based additive technologies: working principle, microstructure and mechanical properties of fabricated builds}

The underlying concept for fabricating materials by friction is relatively simple. As conveyed by the word 'friction; consolidation of a part is achieved by bringing two surfaces in vigorous contact by rubbing or rotation. As these surfaces mate, intense heat is generated at the interface leading to localised rise in temperature which in turn softens the material allowing it to flow and consolidate. Throughout the process, the peak temperature is maintained below the solidus of the alloy and interestingly enough, for most of the times, the process is self-regulating ensuring that joining occurs in solid state without melting. Figure 1 compartmentalises these friction-based technologies on the basis of their working principle.

\subsection{Rotary friction welding $(R F W)$}

One of the early friction-based technologies to be demonstrated as a potential candidate for AM was rotary friction welding by The Welding Institute, UK (Threadgill and Russell, 2007). As illustrated in Figure 1, joining in RFW is accomplished by bringing together one part that is held stationary with the other part rotating at a fixed predetermined rate. On achieving surface contact, the axial force is increased and maintained till sufficient material is extruded by severe plastic deformation. In the final stage, axial or upset force is increased with a simultaneous deceleration of rotational rate forging the parts together. There are two variants to this technology depending on how the energy is transferred to the parts for joining. The first variant, direct drive rotary friction welding uses the rotational energy to join and is used predominantly in Europe and Asia. On the other hand the second variant which is, inertia-based rotary welding uses the stored energy in the flywheel for consolidation and is widely employed in North America. 
Figure 1 Classification of existing FBAM technologies on the basis of their working principle (see online version for colours)

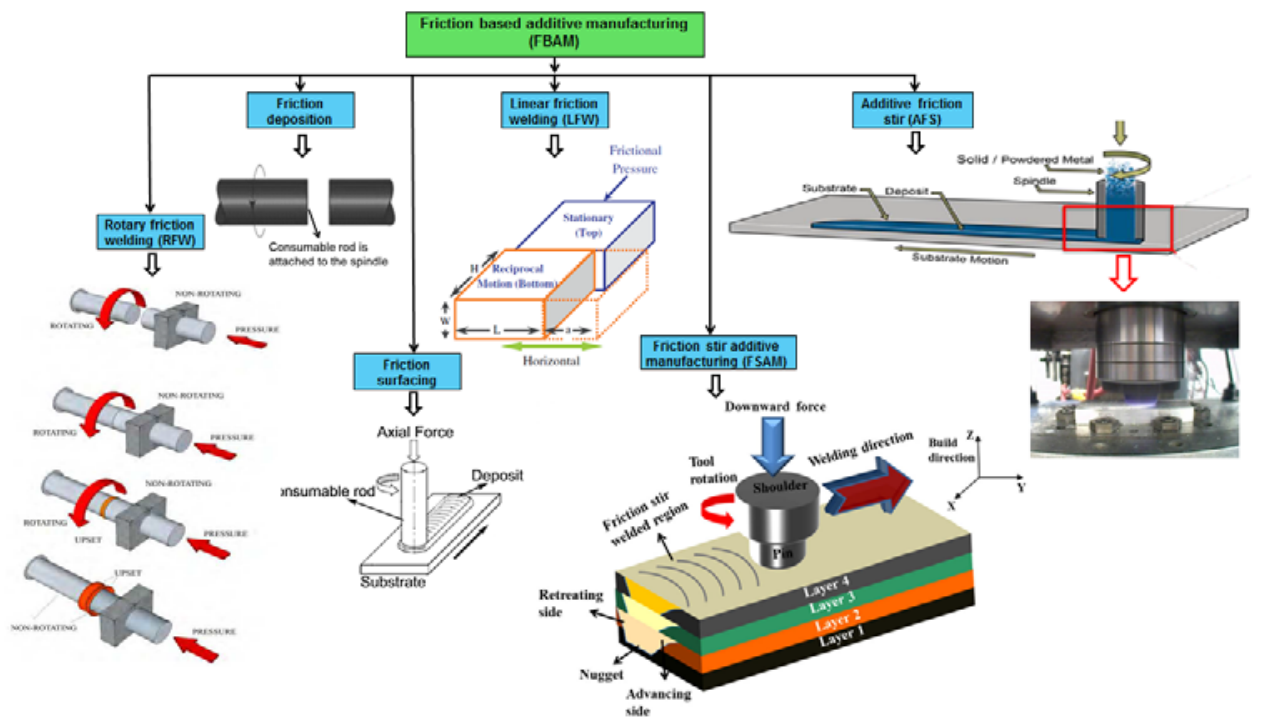

Source: Calvert (2015), Dalgaard et al. (2012), Dilip et al. (2012, 2013),

Kandasamy et al. (2013a), Mateo García (2011) and Palanivel et al. (2015a)

For obtaining a multilayered structure by this technique, sequential addition of parts to the previously joined layers are performed. In other words, if part 2 was welded to part 1 to result in layer 2, welding part 3 to part 2 will result in layer 3 and so on. An advantage of using this technology is that large build volumes can be realised in short times because size of the build is controlled by the dimensions of individual parts which in turn is limited only by the capacity of the machine. Furthermore, the part dimension/layer thickness itself does not impact the time for deposition meaning that for the same number of layers deposited, there is no difference in the build time for fabricating a large or small structure. In such a structure that is fabricated by RFW, the microstructure is affected by three process variables which are; rotational speed, upset force and time for joining. Using this technique, at present, layers with cross-sectional areas as large as $450 \mathrm{~mm}^{2}$ can be deposited using high end machines (Dilip et al., 2012). However the limitation of this technique is that it can only be used to build round symmetrical components like cylinders, rods, axels, pipes, shafts, compressor drums, disks and tubings.

Figure 2 shows a six layered cylindrical stainless steel (AISI 310) structure (length: $78 \mathrm{~mm}$, diameter: $20 \mathrm{~mm}$ ) containing a fully enclosed internal cavity that was fabricated using rotary friction welding (Dilip et al., 2012). Being a hybrid manufacturing technique where machining operations are required in between building steps, this technology fits applications which require assembling small blocks into large structures. With a fine grained layer interface resulting from multiple events of dynamic recrystallisation spawned by high temperature and strain rates, the properties are often at par with the parent material. Tensile properties of the build fabricated by RFW are summarised in Table 1 which also includes mechanical properties of builds that were fabricated using other FBAM processes. 
Figure 2 (a) Photograph of cylindrical stainless steel build (AISI 310) after the deposition of third layer (b) Cross-sectional macrograph showing a total of six deposited layers with layer-interfaces and a fully embedded internal cavity (c) Optical microstructure recorded at the layers 1-2 interface showed sound bonding and a fine grained structure (d) Examples of the failure location which was at the interface of the build (Dilip et al., 2012) (see online version for colours)

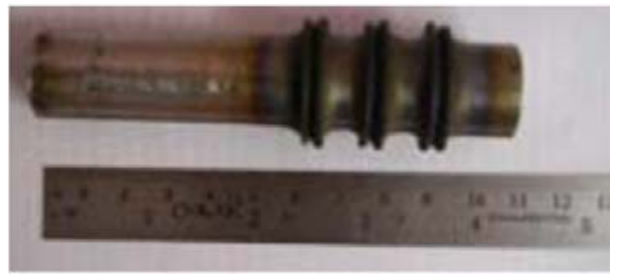

(a)

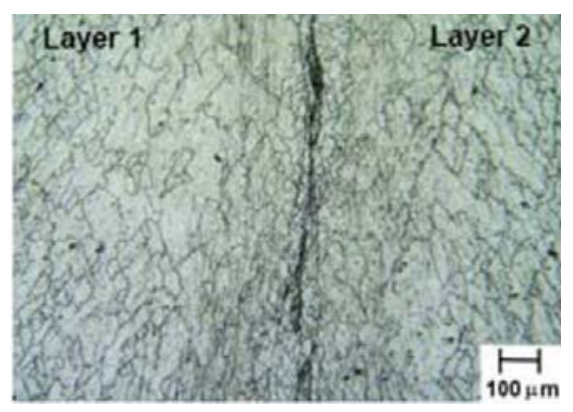

(c)

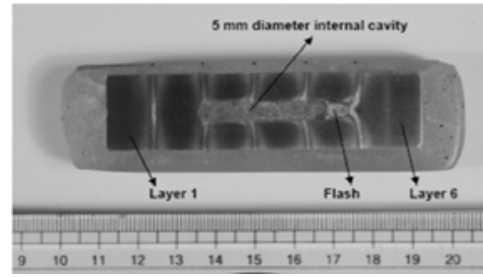

(b)

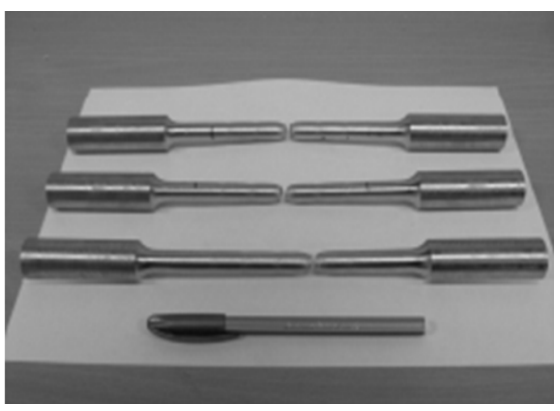

(d)

One major limitation of RFW when compared with powder-based or wire feed fusion technologies is that unlike fusion-based processes where every layer is fused leading to a structure with weld microstructure, the structure built by RFW consists of a thermo-mechanical zone, heat affected zone, welded interface and parent material within a single layer. Co-existence of these three microstructural conditions results in inhomogeneous properties along the build direction, which, depending on the application could be undesirable. Also, due to flash generated at the layer interfaces, depending on the application, a surface finishing operation is required.

\subsection{Friction deposition}

To avoid different microstructural zones/conditions within a single layer, a slightly modified version of RFW was introduced and termed as friction deposition (Dilip et al., 2012). In this technique, instead of joining two parts, a consumable rod is attached to the spindle and brought in contact with the stationary substrate. Similar to RFW, when the rotating consumable rod mates with the stationary substrate, material is plasticised and flows. Upon achieving the desired layer thickness, the process is terminated and substrate on the stationary side is moved away from the rotating rod. The end result is a deposit of desired thickness on the substrate which is equivalent of a single layer. To achieve a tall build with say, $\mathrm{x}$ number of layers, $\mathrm{x}$ number of deposition and machining events are performed. Here, machining is important to ensure that deposit and surface of the rod are flat for better contact when brought together. Note that unlike the RFW process, and 
similar to fusion-based processes, the built structure is fully characterised by weld microstructure. However, the microstructure achieved by friction deposition involves solid-state transformations and is therefore stronger than the solidified microstructure resulting from fusion-based processes.

Figure 3 (a) Photograph of fully deposited $50 \mathrm{~mm}$ tall cylindrical stainless steel build (AISI 304) consisting more than 30 layers (b) Optical micrograph showing fine-grains in the deposit with an average grain size of $20 \mu \mathrm{m}$ (c) Microstructure of the base (consumable rod) material with grain size of $50 \mu \mathrm{m}$ (d) Scanning electron micrograph showing the transition interface between the sensitised and unsensitised layers in the build (see online version for colours)

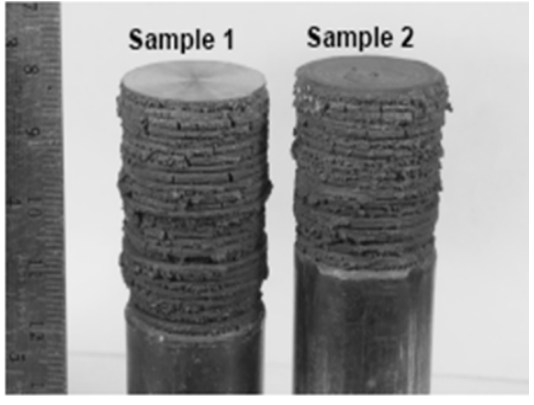

(a)

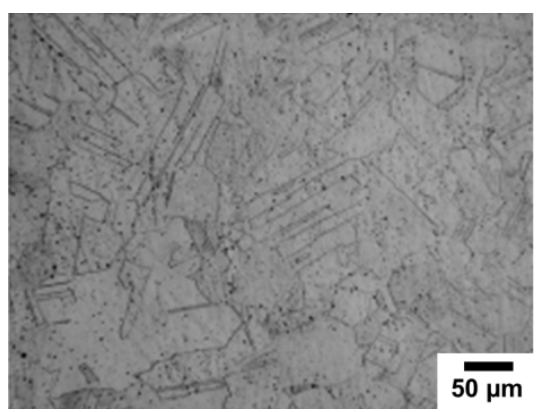

(c)

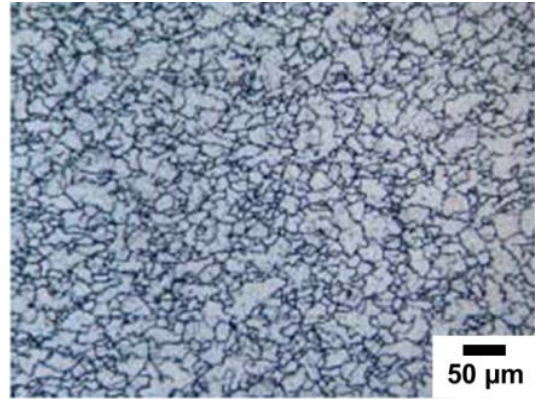

(b)

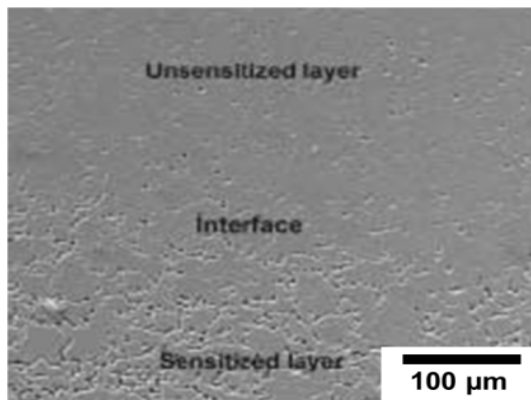

(d)

Source: Dilip et al. (2012)

Figure 3 shows the microstructure of a $50 \mathrm{~mm}$ tall stainless steel (AISI 304) cylinder built by depositing more than 30 layers, each with a thickness of $1.5 \mathrm{~mm}$ (Dilip et al., 2012). As shown in Figure 3(b), grain size was finer in the deposit than base material [Figure 3(c)]. However, as reported by Dilip et al. (2012), sensitisation had occurred in all the layers except the top three layers which received minimal effect from thermal cycling during deposition. Figure 3(d) captures this gradation in the microstructure along the build direction. On the basis of build properties that are summarised in Table 1, it can be concluded that the technique is a suitable route to achieve circular cross-sections with properties similar to base material. 
Table 1 Summary of mechanical properties in builds fabricated using FBAM technologies

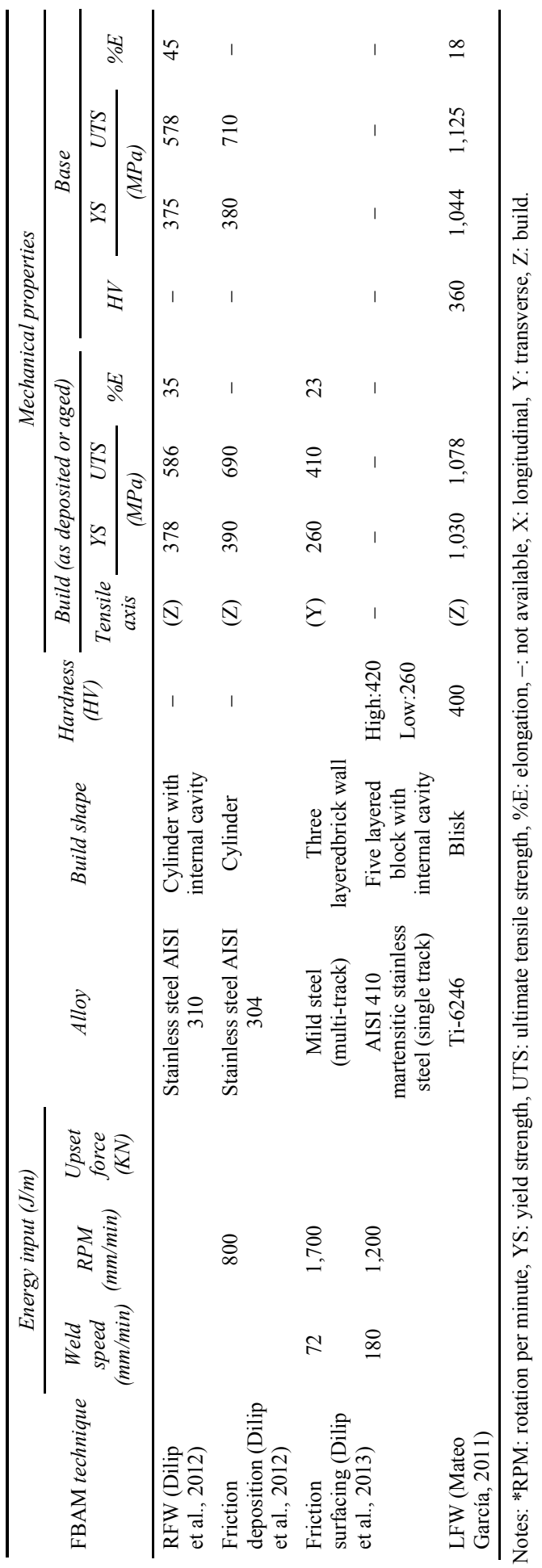


Table 1 Summary of mechanical properties in builds fabricated using FBAM technologies (continued)

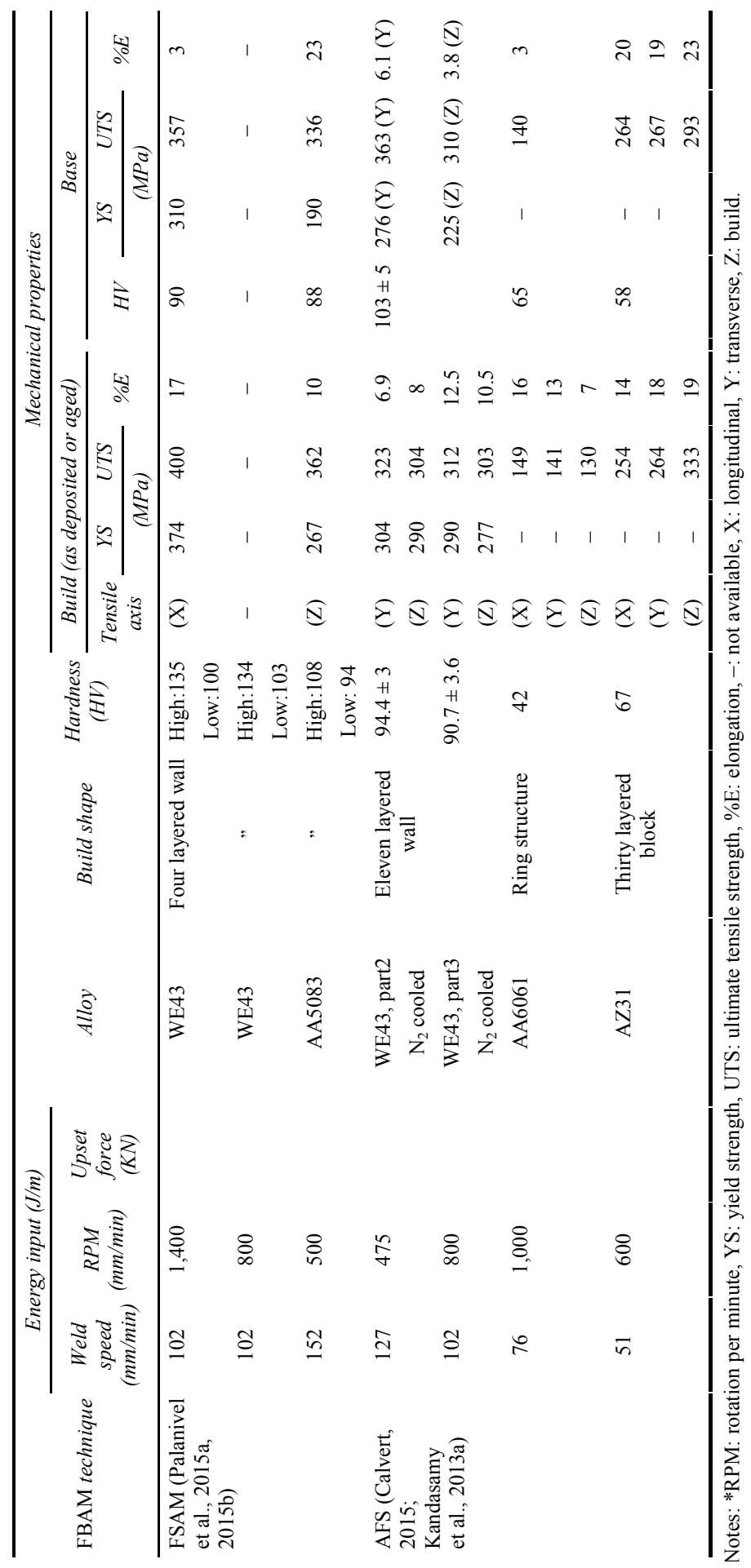




\subsection{Friction surfacing}

Developed as a surface engineering tool, friction surfacing is another technology that has been demonstrated as a prospective $\mathrm{AM}$ technique. In this technique, a metallic consumable rod known as the mechatrode is rotated and pressed against the substrate material by applying axial load. Once the rod tip reaches a temperature capable of generating a viscoplastic boundary layer, bonding occurs by the diffusional processes between the softened material and the substrate. As the plasticised material consolidates due to higher rate of heat conduction through the substrate, with increasing dwell time, several viscoplastic shearing interfaces form with each one increasing the thickness of the layer. Once the desired layer thickness is achieved at the start position, the mechatrode is traversed along the surface of the substrate to deposit the first layer (Gandra et al., 2014). In cases, where the dimension of substrate is much larger, multiple tracks are run adjacent to each other to cover the entire substrate and form the first layer. After depositing the first layer across and along the substrate, the second layer is deposited after machining the first layer for a flat surface. Note that the layer dimensions in this technique are controlled by the dimensions of the consumable rod similar to friction deposition. But unlike the RFW and friction deposition AM techniques which are limited to circular geometries, friction surfacing can be used to build parts with other shapes.

Figure 4 (a) Schematic showing multi-track, multi-layered structure built using friction surfacing (b) Photograph showing multiple overlapping tracks adjacent to each other in a single layer (c) Photograph of the built structure (d) Micrographs showing full consolidation between the tracks and layers (e) Micrograph highlighting lack of consolidation between tracks due to improper positioning of mechatrode
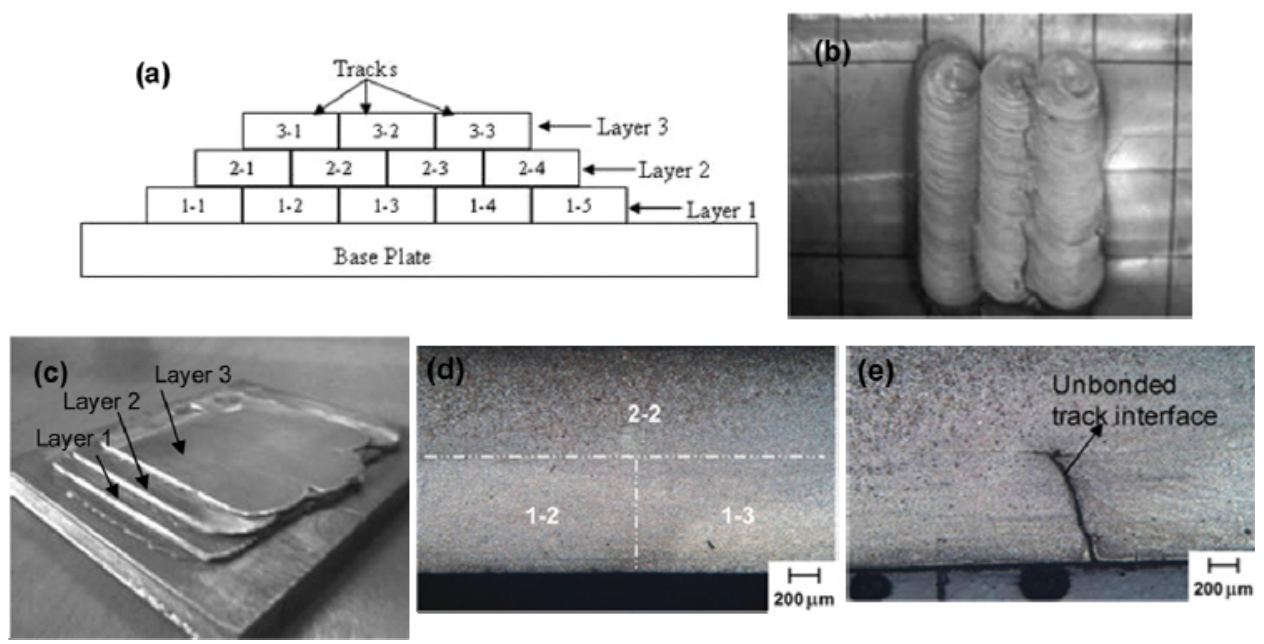

Notes: In (a), first and second numbers denote layer and track, respectively. For example $1-3$ is first layer and third track.

Figure 4 shows a multi-track, multi-layered mild steel build fabricated using friction surfacing (Dilip et al., 2013). Five tracks were deposited in this study to form the first layer which decreased to four and three tracks in the progressive layers (Dilip et al., 2013). The measured mechanical properties (Table 1) along the build direction (tensile 
strength: $410 \mathrm{MPa}$, elongation: $23 \%$ ) were at par with the wrought properties due to sound consolidation and refined grain size. To achieve good bonding between the individual layers in a multi-track multi-layered structure, it is necessary that the mechatrode is optimally positioned. In the case of single track-multi layer, this is not as critical but still required. The other factors that play significant role in controlling the microstructure are substrate thickness, rod dimensions, axial force, rotational speed and travel speed. Detailed role of these process variables on the evolving microstructure has been reviewed by Gandra et al. (2014) on friction surfacing.

\subsection{Linear friction welding (LFW)}

Linear friction welding (LFW) is a technique that is gaining immense interest for the fabrication of blisks which is an integrated assembly of blades and disks in the aerospace industry (Bhamji, 2012; Caldara, 1987; Hiroshi et al., 2014; Kallee et al., 2003). Such an assembly has several advantages over the conventionally riveted blades to the disks, one of which is weight reduction. The operating principle of LFW is similar to RFW with the one major difference being that friction between two parts is no more generated by rotating and forging but by rubbing two surfaces while applying a load. In this technique, one of the parts that need to be joined is oscillated at a specified frequency and amplitude while the other is kept stationary. The heat flux into the interface is therefore a function of oscillation frequency, amplitude and the axial load applied and can be controlled by varying them. For example, if components like turbine blades are being worked upon, the frequency can be increased at fixed amplitude of oscillation to reduce the axial forces and hence buckling (Vairis and Frost, 1998). Controlling these build variables influences the final microstructure in the built component and hence determines the mechanical integrity.

Another similarity between RFW and LFW is that the components built by LFW also possess welded, thermo-mechanically affected, heat affected, and parent material zones. But the width of the heat affected zone in LFW is lesser because the peak temperature is attained at the centre in contrast to RFW builds where maximum temperatures are experienced away from the centre (Vairis, 1997). Conceptually, the way consolidation is achieved in LFW can be categorised into four stages. In the first stage known as the contact stage, attrition of the asperities occur at the interface followed by a second stage during which these worn surface features are ousted allowing for the plasticisation of material due to the friction created at the interface. In the third stage, axial pressure is increased causing further softening of the material as it extrudes in the form of flash. In the final stage known as the forging phase, the process is stopped after achieving the desired shortening and consolidation is achieved by aligning the parts and increasing the axial pressure (Wanjara and Jahazi, 2005). Repetition of this process results in a multilayered structure where each added part is equivalent to adding a layer. An advantage of this process over RFW and friction deposition is that the technique is not limited to manufacturing axisymmetric builds and can be used for building relatively complex geometries. Since this review is restricted to AM by using these technologies, details about the conventional use of this process for welding has been limited. To get in-depth information on the RFW and LFW process, the readers can refer to a recent review article by Chamanfar et al. (2015). 


\subsection{Friction stir additive manufacturing (FSAM)}

The first major push for using friction stir welding as an AM route was provided by Airbus and Boeing (Lequeu et al., 2006; Baumann, 2012). While Airbus (Lequeu et al., 2006) demonstrated the ability to achieve low cost-lightweight structures by fabricating 2050 Al-Li wing ribs by FSAM, Boeing (Baumann, 2012) evaluated the technology as a pre-form building tool for fabrication of energy efficient structures. Based on the case studies carried out at these two organisations, they arrived at the following conclusions:

1 technology is capable of achieving high throughput leading to faster production rates

2 less material wastage by using FSAM.

In addition to reducing cost and saving energy, recent studies by Palanivel et al. (2015a, 2015b) demonstrated FSAM as a technique for producing high performing structures.

Table 2 Process variables influencing microstructural evolution in friction-based additive technologies

\begin{tabular}{ll}
\hline FBAM technique & \multicolumn{1}{c}{ Factors affecting microstructural evolution } \\
\hline $\begin{array}{l}\text { Rotary friction } \\
\text { welding }\end{array}$ & $\begin{array}{l}\text { Rotational speed, upset force, friction force, time for joining, burn off } \\
\text { length }\end{array}$ \\
$\begin{array}{l}\text { Friction deposition } \\
\text { Friction surfacing }\end{array}$ & $\begin{array}{l}\text { Rotational speed, friction force, time for deposition, burn off length } \\
\text { Position of mechtrode, rotational speed, axial force, traverse speed, } \\
\text { consumable rod dimensions }\end{array}$ \\
$\begin{array}{l}\text { Linear friction } \\
\text { welding }\end{array}$ & $\begin{array}{l}\text { Frequency and amplitude of oscillation, friction pressure, forging } \\
\text { pressure, forging time, decay time, ramp-up time }\end{array}$ \\
FSAM & $\begin{array}{l}\text { Tool geometry and features, backing plate or any other cooling fixture, } \\
\text { rotational speed, traverse speed, sheet thickness, forge force } \\
\text { Tdditive friction stir }\end{array}$ \\
& $\begin{array}{l}\text { Tool geometry, spindle speed, traverse speed, filler feed rate, tool } \\
\text { fixture, substrate thickness }\end{array}$ \\
\hline \multicolumn{2}{c}{ Source: $: \begin{array}{l}\text { Bertrand (2014), Chamanfar et al. (2015), Dilip et al. (2012), Gandra } \\
\text { et al. (2014), Kandasamy et al. (2013a) and Palanivel et al. (2015a) }\end{array}$}
\end{tabular}

The basic working principle of FSAM is similar to friction stir welding. As illustrated in Figure 1, in FSAM, a multilayered build is manufactured by inserting a non-consumable tool into the overlapping/abutting sheets or plates to be welded and traversed along the joint line. Frictional contact between the tool and workpiece coupled with intense plastic deformation achieved by the shear deformation supply heat and contribute to the softening of material. As the tool rotates and advances, consolidation of the build occurs by the movement of softened material from the front to the back of the pin. When compared to previously discussed techniques where heat was generated by friction between the layers to be deposited or joined, in FSAM, heat is generated between a third body (tool) and the layers that need to be consolidated. Due to this characteristic, greater control is exercised over the microstructure leading to better properties. In this technique, final build height depends on the thickness of each layer and the number of assembly stages/layers. Furthermore, modifications in the design geometry can lead to builds with different geometries. In FSAM, the overall kinetics of microstructural evolution depends on the thermal cycle, strain and strain rate which are controlled by the process variables that include rotational rate, traverse speed, tool geometry and forge 
force as mentioned in Table 2. Detailing the exact role of these variables is out of the scope of this article and the reader is encouraged to refer to the textbook by Mishra et al. on friction stir welding (Mishra et al., 2014).

Figure 5 (a) Cross-sectional macrograph (b) Hardness profile along build direction

(c) Uniaxial tensile stress-strain curve from the circled location in (b) of WE43 build fabricated using 1,400 rpm and $102 \mathrm{~mm} / \mathrm{min}$ by FSAM (d) Micrograph showing the fine grain size in layer 1 from which the sample was extracted for tensile testing (e)-(f) The cross-sectional macrograph and hardness profile along the build direction in an AA5083 alloy manufactured using $500 \mathrm{rpm}$ and $152 \mathrm{~mm} / \mathrm{min}$ (Palanivel et al. 2015a, 2015b) (see online version for colours)

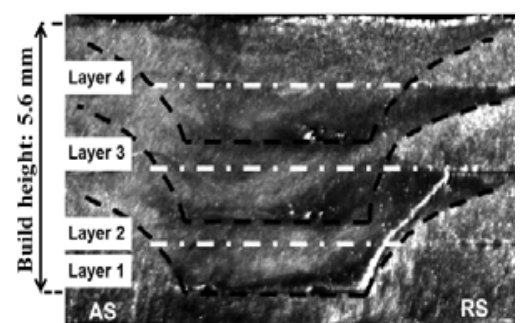

(a)

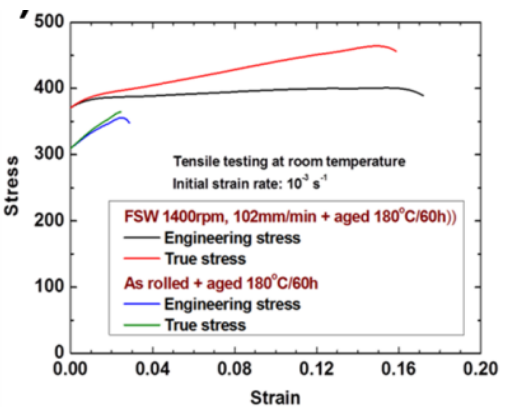

(c)

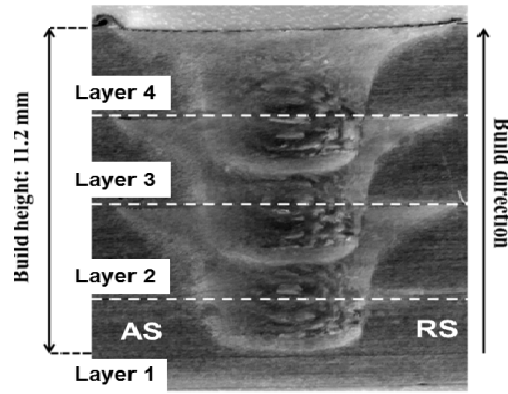

(e)

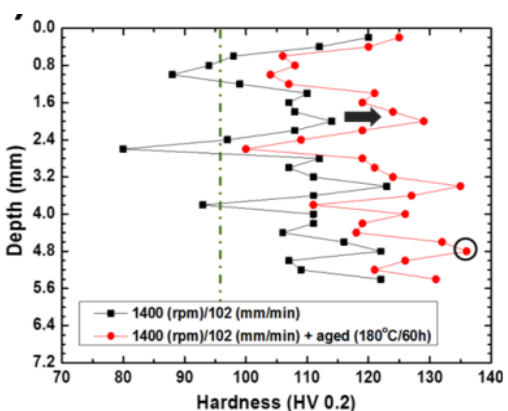

(b)

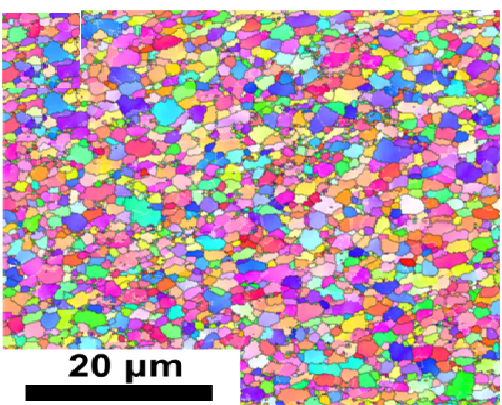

(d)

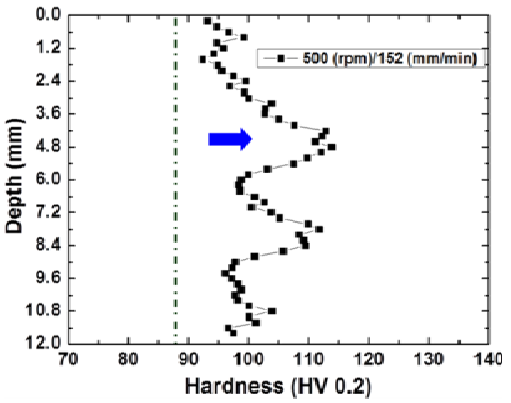

(f)

Notes: Note that in (d) strength and ductility were significantly higher in FSAM build than the wrought sheet that was used for building. (e)-(f) hardness was higher in all the locations in the $\mathrm{Mg}$ and $\mathrm{Al}$ alloy build as compared to the hardness in base material (denoted by vertical dashed line) 
Figures 5(a) and 5(e) shows the macrograph of Mg (WE43) and Al alloy (AA5083) builds fabricated using FSAM (Palanivel et al., 2015a, 2015b). As shown in Figure 5 and summarised in Table 1, excellent mechanical properties were reported in these builds. Specifically, in the rare earth containing $\mathrm{Mg}$ alloy build, strength reached $400 \mathrm{MPa}$ [Figure 5(c)] which matched $2 \mathrm{XXX} \mathrm{Al}$ alloys. These strength values were correlated to the formation of extremely fine, uniform and densely populated coherent precipitates in the size range of 2-7 $\mathrm{nm}$ (Palanivel et al., 2015a). In addition, six fold increase in ductility (17\%) was reported in comparison to the wrought material (3\%) and was correlated to the fine grain size [Figure 5(d)] facilitated deformation behaviour. Furthermore, the structure was stronger than the base material in all the locations as illustrated by the hardness profile of $\mathrm{Mg}$ and $\mathrm{Al}$ alloy builds in Figures 5(b) and 5(f). On the basis of these results Palanivel et al. (2015a) claimed that builds with properties better than wrought material can be produced using FSAM and indicated its potential for manufacturing high performance parts.

\subsection{Additive friction stir (AFS)}

To this point, all the technologies discussed above were hybrid in nature meaning that both additive and subtractive steps were necessary for building the component. A modification of the friction stir welding technique, additive friction stir (AFS), is a process that is purely additive in nature. It also differs from the above mentioned FBAM technologies in the aspect that the starting material can be powder while wrought sheets, plates or tubes that are necessary for the other friction techniques can also be used. Though AFS closely resembles powder-based fusion AM processes on the basis of input material, the way in which the feed material is consolidated differs. Unlike fusion-based process where powders are melted, AFS softens the powder and consolidates them, thereby, avoiding porosities and other solidification defects presented by powder-based fusion AM technologies.

Figure 1 shows a schematic of the AFS process where a consumable filler stock in the form of solid/powder is used as the starting material (Calvert, 2015). Utilising pressure from a rotating non-consumable tool to generate heat and plastic deformation, this filler material is added through its centre. As the consolidated filler material is extruded through the centre of the tool, the custom designed tool builds the requisite geometry on the basis of the application. For achieving a sound bonding between the substrate and filler material, it is necessary to ensure sufficient hydrostatic pressure and heat from the frictional and adiabatic processes (Kandasamy et al., 2013a). Using this technique, it is possible to deposit individual layers with overlapping tracks, and after depositing a full layer of the desired geometry, the tool is raised equivalent to the layer thickness for the deposition of the next layer which in principle is similar to powder bed fusion processes. During the entire course of the process, the filler material is forced into the previous layer creating diffuse layers with superior bond strength while the dynamic shape of filler aids in the fabrication of the component as it is being consumed. A major difference between the FSAM and AFS process is that FSAM consolidates the material by inserting a pin into it whereas AFS consolidates the feed material within the tool and deposits it by extruding it through its centre. Since AFS does not have pin/probe in the tool like FSAM which penetrates into the base metal, the tool complexity is greatly reduced. However, similar to FSAM, the resulting microstructure is fine grained, highly randomised, and homogeneous resulting in isotropic properties. 
Figure 6 (a) A multilayered Al alloy built using AFS. Microstructures of WE43 alloy fabricated using (b) $-100 /+325$ atomised powder (part 2) and (c) feed rod cut from rolled plate as starting material (part 3) (d) Higher yield and ductility was observed in the built parts when compared to the wrought condition (WE43-T5) (e)-(f) Layer wise variation in hardness and uniaxial tensile properties in part 2 (Calvert, 2015) (g)-(h) Cross-sectional macrographs of AA6061 ring and AZ31 block built by AFS (see online version for colours)

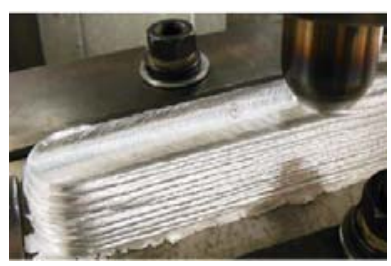

(a)

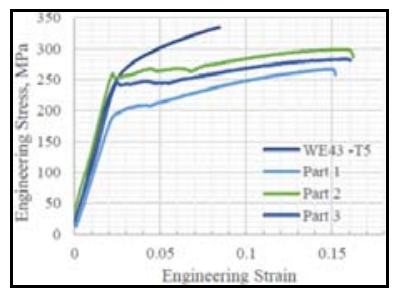

(d)

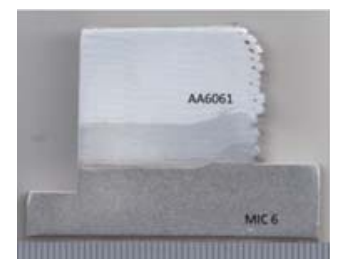

(g)

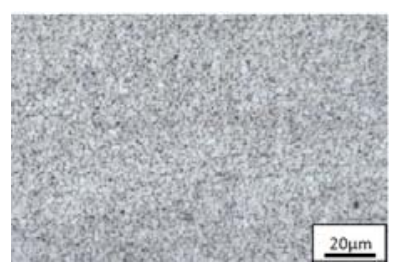

(b)

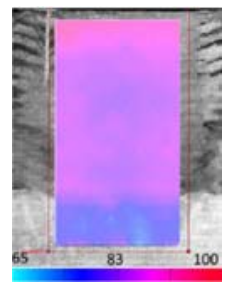

(e)

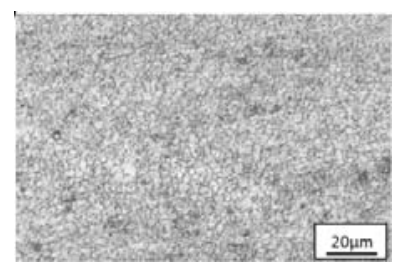

(c)

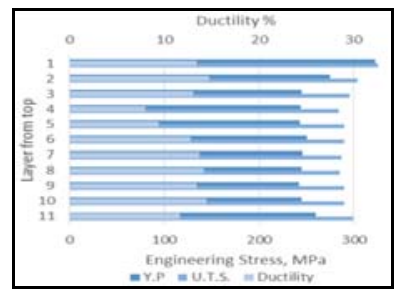

(f)

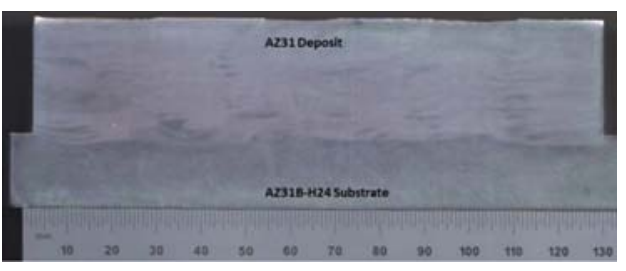

(h)

Note: Parts 1 and 2 in (d) were built at $450 \mathrm{rpm}$ and $127 \mathrm{~mm} / \mathrm{min}$ using powder feed and different cooling mediums whereas part 3 was built at $800 \mathrm{rpm}$ and $102 \mathrm{~mm} / \mathrm{min}$.

Source: Kandasamy et al. (2013a)

Figure 6 shows a multilayered Al alloy build and the microstructures in a WE43 alloy built using AFS (Calvert, 2015). Similar to the above techniques, a fine grained microstructure (grain size: $2 \mu \mathrm{m}$ ) was reported using this technique which resulted in better yield and elongation values in comparison to the wrought substrate along the build and transverse directions. Also shown are the cross-sectional macrographs of AA6061 ring and AZ31 block built using AFS (Kandasamy et al., 2013a). The uniaxial properties of these builds are also summarised in Table 1 along with WE43. Additionally, the study (Calvert, 2015) showed homogeneous distribution of microstructure leading to isotropic properties which was achieved by controlling the process variables that include rotational rate, traverse speed, cooling rate, all of which are mentioned in Table 2. The build examples of $\mathrm{Mg}$ clearly illustrate that issues like powder vaporisation and directionality which cause concerns in fusion-based AM are non-existent and resolved in FBAM techniques. 
Table 3 Advantages and limitations of FBAM technologies

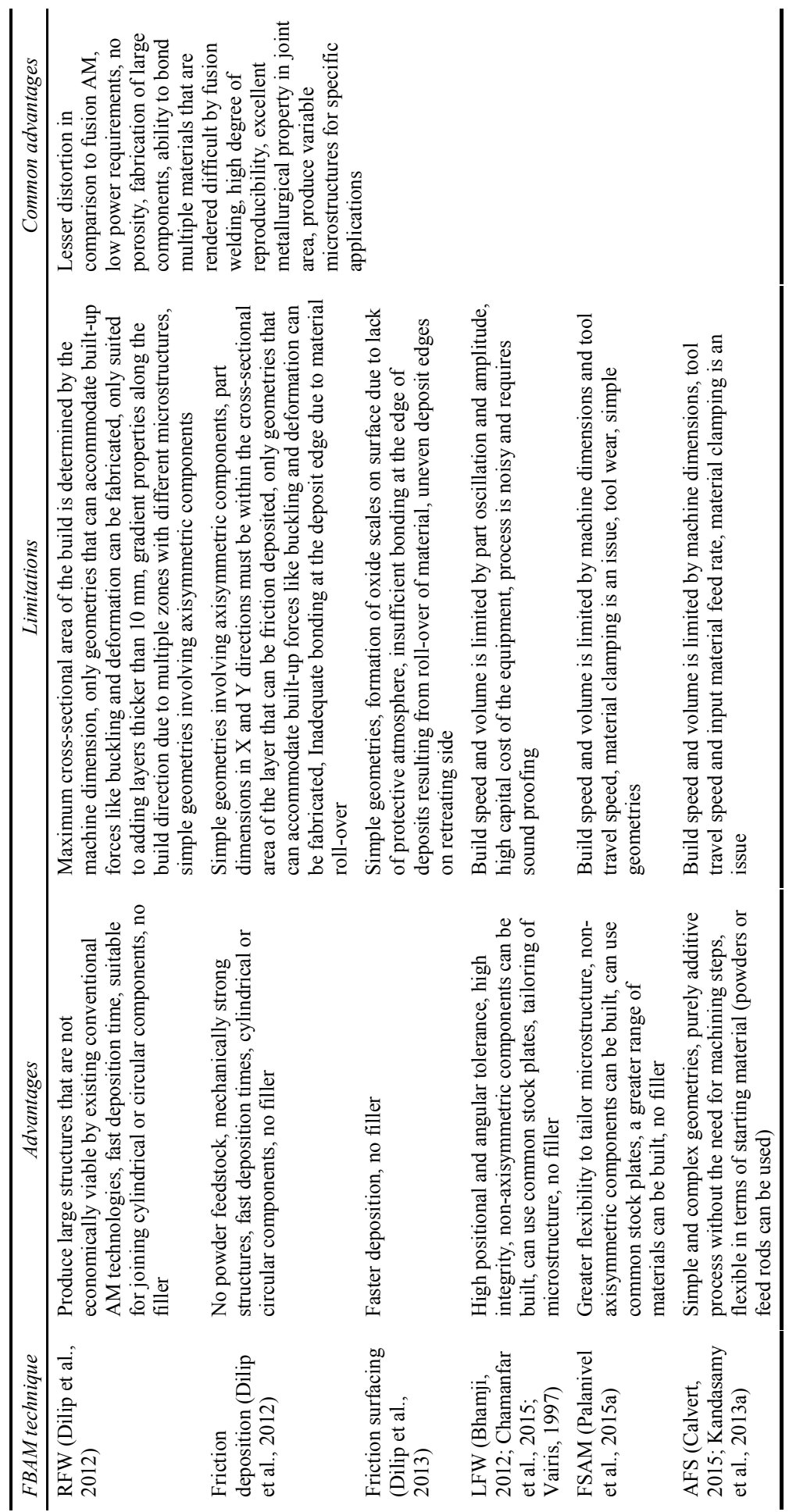




\section{Advantages and limitations of friction-based additive technologies in comparison to fusion $\mathrm{AM}$}

Table 3 lists and contrasts the advantages and limitations of individual FBAM technologies. In addition to the presented differences over one another and fusion-based $\mathrm{AM}$, the purpose of the summary is to provide guidance in selecting or deselecting a specific FBAM technique for a certain application. When compared to fusion-based AM processes, FBAM technologies offer advantages on three fronts which are:

1 energy consumption

2 part consolidation

3 structural integrity.

While the first advantage contributes to the drive for sustainability by reduction of greenhouse gases, the other two are associated with part performance.

A recent study designed a methodology to calculate the mean power consumption and the specific energy efficiency of fusion additive processes (Baumers et al., 2011). Based on the method, around $2-3 \mathrm{KW}$ of mean power was required for fabricating a build. Considering the EOSINST laser-based process at full capacity utilisation, specific energy efficiency was reported between 100-400 MJ/kg (Baumers et al., 2011). Compared to such energy demands, friction-based processes consume minimal energy $(\sim 2.5 \%$ of fusion-based process for FSAM) (Mishra and Ma, 2005). Additionally, the heat flux in laser and electron beam AM is $\sim 10^{7} \mathrm{~W} / \mathrm{m}^{2}$ which is significantly higher than friction-based techniques $\left(\sim 10^{3} \mathrm{~W} / \mathrm{m}^{2}\right)$ (Mendez and Eagar, 2002). Due to higher heat flux in fusion-based AM that is required for melting, intense thermal gradients develop within the build leading to residual stresses and therefore part distortion which is reduced in FBAM processes to a great extent. Also, since melting is involved in fusion-based techniques, solidification defects like porosities and shrinkage cavities develop leading to lower mechanical properties. Since the evolution of porosities is highly stochastic in nature, it is difficult to control them, an issue that is completely eliminated in FBAM. The third advantage - high structural performance in FBAM arises due to the difference in the way a part is built using friction and fusion-based AM. While fusion-based processes lead to builds with cast microstructures with inferior properties, friction-based processes result in builds with wrought microstructures and hence better properties.

Inspite of the above advantages, two key challenges restrict FBAM from penetrating into the main stream market. These are:

1 capital cost involving machinery

2 inability to fabricate highly complex structures.

Since AM is justified primarily by these two criterion which is, the ability to make complex shapes economically, further research focused on cost benefit analysis and technology development is needed for FBAM to qualify as a mainstream technique. The above discussed qualities of fusion-based and FBAM are placed into perspective in Figure 7. 
Figure 7 Fusion and FBAM technology domains illustrated by schematic using energy efficiency, structural performance, part distortion, and part complexity as the measuring yardsticks (see online version for colours)

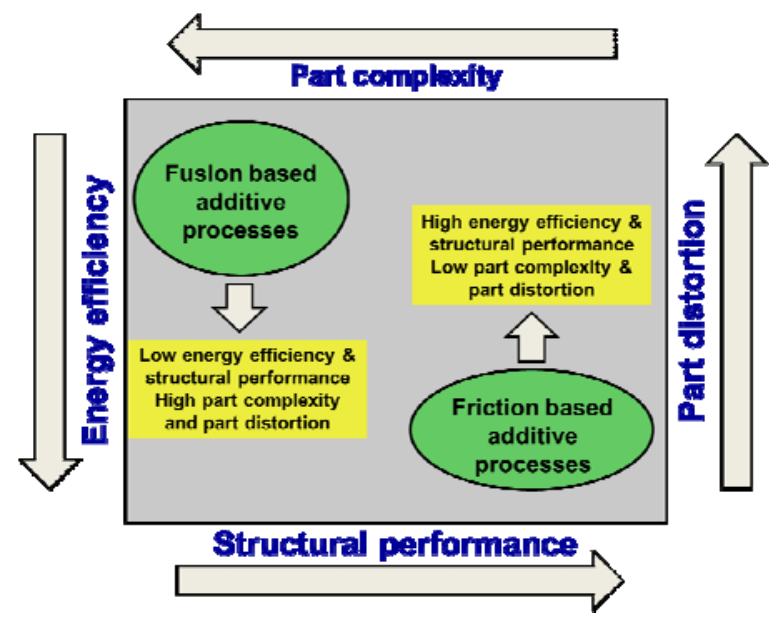

An FBAM technique that shows promise for addressing the complexity aspect is AFS. While, a majority of the FBAM techniques are hybrid in nature and serve the purpose of adding features to a component, the completely additive nature of AFS with minimal need for machining is suitable for generating features. However, unlike fusion-based techniques where any geometry can be visualised and built, only shapes that can be accommodated by the machine can be built. Furthermore, for complex shapes, a custom built fixturing might be required and will add to the cost of the component. These limitations are similar to the FSAM process, where the build volume and geometry is limited by the dimensions and ability of the machine. One potential way to address this drawback would be to use robotic machines with greater flexibility. A detailed comparison between the FBAM techniques is drawn by listing the individual capabilities and limitations in Table 3 shown above.

\section{Scope of friction-based additive technologies}

Accessing spaces that are inaccessible to fusion-based AM techniques is possible using FBAM technologies. One area where FBAM can add to the portfolio of metal AM is in fabrication of high strength Al alloy structures which are not buildable using the existing fusion-based additive techniques due to hot cracking issues. Extending FBAM for high strength ( $>400 \mathrm{MPa}) \mathrm{Al}$ alloys $(2 \mathrm{XXX}$ and $7 \mathrm{XXX})$ can widen the scope of the AM field by penetrating into the aerospace industry where $\mathrm{Al}$ consumption is to the tune of $\sim 630$ million pounds accounting for $48 \%$ of total raw material used annually. The bigger picture of the supposed benefits of utilising FBAM in the aerospace industry was provided by Boeing (Baumann, 2012) which estimated a volume reduction of nearly five billion pounds of $\mathrm{Al}$ and emission of 60 billion pounds of $\mathrm{CO} 2$ over the next 25 years by using LFW, RFW and FSAM for manufacturing pre-forms. This report concluded that a shift from the current machining out approach to the building up approach by FBAM will transcend into the sustainable manufacturing space, an advantage that is restated here. In 
addition to fabricating $\mathrm{Al}$ alloys, FBAM is best suited for building structures made of alloys that possess high hall-petch strengthening ability due to the extremely fine grain sizes that result from the various friction processes. Within this category fall a majority of structurally pertinent lightweight $\mathrm{Mg}$ alloys along with high temperature titanium alloys and steels.

Beyond the potential to manufacture structures made up of a single alloy is the possibility to build graded structures comprised of multiple materials. At present, manufacturing such functionally tailored structures by the existing fusion-based AM processes is a challenge because of the differential thermal expansion coefficients of two alloys/materials that need to be fused. In cases, where this challenge is circumvented, avoiding undesirable intermetallic formation becomes a key issue (Hofmann et al., 2014). Since FBAM operates in solid state, the concern for thermal expansion is completely avoided while the intensified shearing during the process aids in controlling the size and distribution of intermetallics at the interface. The fundamental principle of the FBAM techniques makes it a viable route to fabricate graded structures.

Table 4 Current and potential applications of FBAM techniques

\begin{tabular}{|c|c|c|}
\hline Technology & Current applications & Potential applications \\
\hline $\begin{array}{l}\text { Rotary friction welding } \\
\text { (Dilip et al., 2012; } \\
\text { Threadgill and Russell, } \\
\text { 2007) }\end{array}$ & $\begin{array}{l}\text { Joining a range of } \\
\text { components like actuators, } \\
\text { undercarriage parts, } \\
\text { fixings and engine } \\
\text { structure }\end{array}$ & Dissimilar metal AM, adding bosses \\
\hline $\begin{array}{l}\text { Friction deposition } \\
\text { (Dilip et al., 2012) }\end{array}$ & & $\begin{array}{l}\text { Round Parts with internal cavities can } \\
\text { be fabricated, gradient structures }\end{array}$ \\
\hline $\begin{array}{l}\text { Friction surfacing } \\
\text { (Dilip et al., 2013) }\end{array}$ & & $\begin{array}{l}\text { Corrosion and wear resistant coatings, } \\
\text { components with fully enclosed } \\
\text { internal cavity or/and features }\end{array}$ \\
\hline $\begin{array}{l}\text { Linear friction welding } \\
\text { (Bhamji, 2012; Caldara, } \\
\text { 1987; Chamanfar et al., } \\
\text { 2015; Hiroshi et al., } \\
\text { 2014; Vairis, 1997) }\end{array}$ & $\begin{array}{l}\text { Manufacture of high } \\
\text { temperature } \mathrm{Ti} \text { alloy } \\
\text { blisks for jet engines. }\end{array}$ & $\begin{array}{l}\text { Best suited for rapid fabrication of } \\
\text { large scale parts from simple structural } \\
\text { blocks, gradient structures, airframe } \\
\text { brackets, small protruding features, } \\
\text { strengthening elements, L frame clips } \\
\text { for aerospace }\end{array}$ \\
\hline $\begin{array}{l}\text { FSAM (Baumann, } \\
\text { 2012; Leque et al., } \\
\text { 2006; Palanivel } \\
\text { et al.,2015b) }\end{array}$ & Manufacturing preforms & $\begin{array}{l}\text { Fabricating stringer on skin in aircraft } \\
\text { fuselage, stiffeners for other high } \\
\text { performance applications: ex: creep } \\
\text { resistance for fossil and nuclear } \\
\text { applications, gradient materials }\end{array}$ \\
\hline $\begin{array}{l}\text { AFS (Calvert, 2015; } \\
\text { Kandasamy et al., } \\
\text { 2013a, 2013b) }\end{array}$ & $\begin{array}{l}\text { Large scale fabrication of } \\
\text { ultrafine grained } \\
\text { functionally graded } \mathrm{Mg} \\
\text { armor }\end{array}$ & $\begin{array}{l}\text { Webbed and ribbed components on } \\
\text { airframes, part fabrication using oxide } \\
\text { dispersion strengthened alloys for } \\
\text { fast-reactor nuclear power generation, } \\
\text { coating of shaft journals for use in } \\
\text { extreme wear and corrosion } \\
\text { applications, increased wear } \\
\text { performance of rails for railgun, } \\
\text { functionally graded materials }\end{array}$ \\
\hline
\end{tabular}

The other shared concern among the metal additive community is that fusion techniques are complexity free but not property flexible. For the FBAM technologies, properties are 
easily tailorable but the complexity is limited. Therefore, the best possible arena for the utilisation of FBAM technologies would be applications which require high performing structural components that are geometrically simpler. Table 4 summarises the current and potential applications of FBAM technologies while Figure 8 illustrates a few of the many different geometric and material configurations fabricated using the FBAM techniques. Figure 8 also shows a few conceptual schematics highlighting the scope of FBAM techniques in aerospace and ship building sectors (Palanivel et al., 2015b).

Figure 8 Geometrical configurations and multi-material prototypes fabricated using FBAM technologies (see online version for colours)

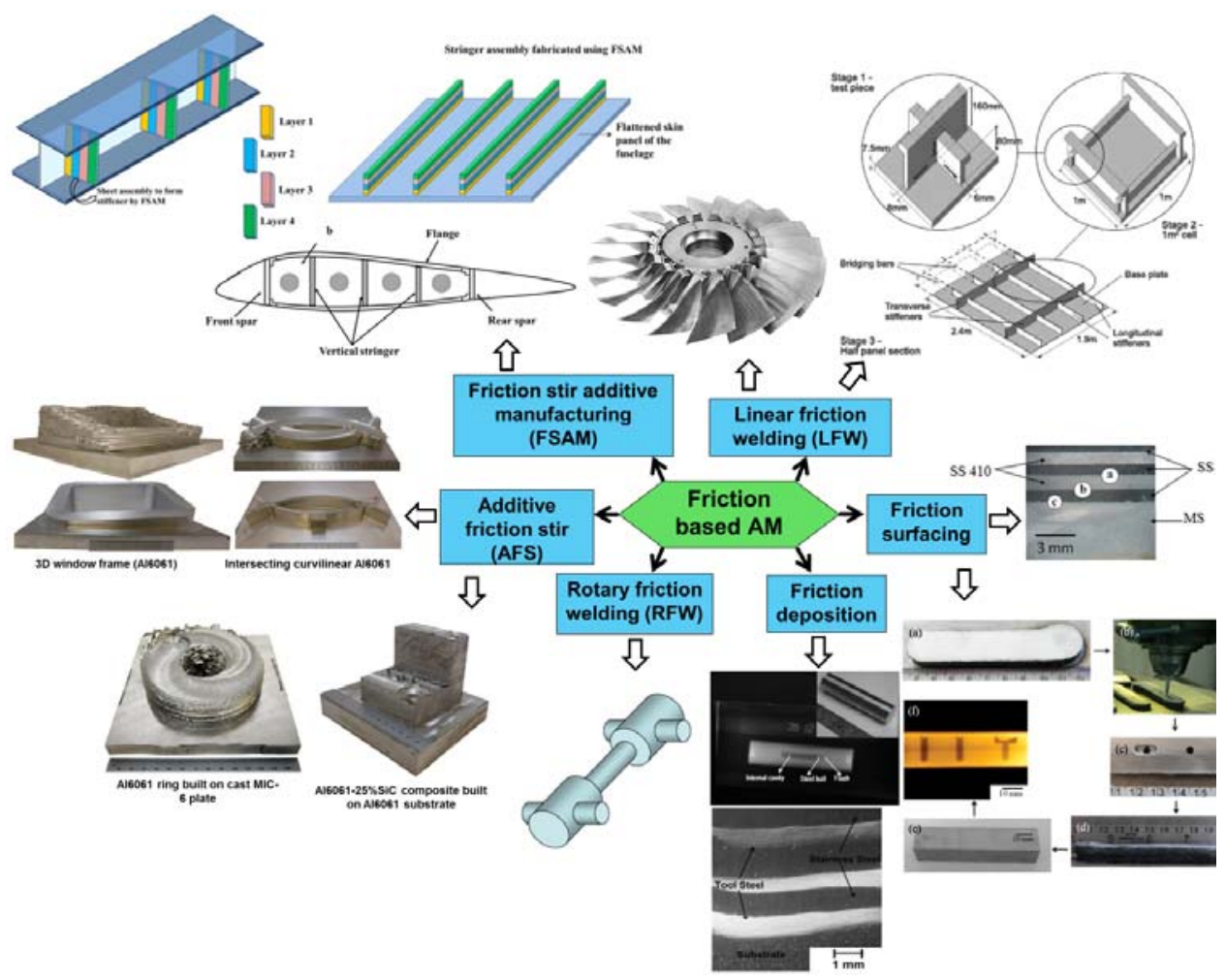

Notes: Potential to fabricate axisymmetric geometries with internal cavities and multi-material gradient structures was previously demonstrated using friction deposition and friction surfacing (Dilip et al., 2012, 2013). Component drawing shows the potential of RFW in aerospace (Threadgill and Russell, 2007). AFS has been demonstrated as a technique capable of generating complex and gradient structures, and composites (Calvert, 2015; Kandasamy et al., 2013a). LFW has been successfully used to produce blisks: an integrated assembly of blades and disks with higher performance. Potential of FBAM technologies is highlighted considering designs for the use of LFW (Woloszyn and Howse, 2001) in shipbuilding applications and FSAM (Palanivel et al., 2015b) for fabricating high performance stiffeners for aerospace sectors.

By performing case studies considering multiple scenarios through which the subtended article for the floor component of Boeing-777 could be manufactured, Boeing concluded that optimal structures with least consumption of energy and minimum buy to fly ratios 
can be achieved by integrating LFW, FSAM and corner angle welding (Baumann, 2012). Similarly, Airbus (Lequeu et al., 2006) and Palanivel et al. (2015a) demonstrated that FSAM can be used to fabricate wing ribs and integrated stringer assemblies on the skin panel of aircraft fuselage. The study (Palanivel et al., 2015b) stressed that the technique is capable of producing structures with variable properties on the basis of the application. Similar to the potential role of the above techniques in the aerospace industry, LFW has been stated as a promising technique for the ship building industry (Woloszyn and Howse, 2001). One of the fast emerging flexible FBAM techniques is AFS that can be used for applications rendered by other FBAM processes with an added advantage of reducing the buy to fly ratio to a greater extent. This process is currently under active investigation by Aeroprobe corp. for railgun applications, aerospace and space sectors, and the energy industry.

\section{Concluding remarks}

With a technology readiness level of four (TRL-4 is defined as component/subsystem validation in laboratory environment; DoD TRL Definition, 2011) for a majority of FBAM processes (RFW, LFW, FSAM, and AFS), FBAM shows promise to evolve into mainstream manufacturing. From expanding the alloy space to enabling multi-material combinations, FBAM has been reviewed as a promising candidate for applications that require high performance but with limited complexity. The inherent nature of the process which does not involve any melting like the existing metal-based AM process coupled with higher metal deposition/addition rates is capable of expanding the window for AM process with further research and progress. Similar to the way fusion-based AM techniques are utilised for fabricating highly complex structures, FBAM techniques show promise for filling the void where simple components with excellent properties are needed due to its principle of 'building without melting'. As AM matures towards high end production, FBAM can be a valuable addition to the existing techniques.

\section{References}

Mateo García, A.M. (2011) 'BLISK fabrication by linear friction welding', in Advances in Gas Turbine Technology, INTECH Open Access, DOI: 10.5772/2127, ISBN: 978-953-307-611-9.

Baumann, J.A. (2012) Technical Report On: Production of Energy Efficient Preform Structures, The Boeing Company, Huntington Beach, CA.

Baumers, M., Tuck, C., Wildman, R., Ashcroft, I. and Hague, R. (2011) 'Energy inputs to additive manufacturing: does capacity utilization matter?', EOS, Vol. 1000, №. 270, pp.30-40.

Bertrand, F. (2014) 'Powerpoint presentation on: near-net-shape manufacturing by linear friction welding', 25th Advanced Aerospace Materials and Processes, Aeromat Conference, Kissimmee, FL.

Bhamji, I.M. (2012) Development of the Linear Friction Welding Process, PhD diss, University of Manchester.

Caldara, S. (1987) Blisks - An Investigation Into the Linear Friction Welding of Titanium Alloy IMI 318, B. Eng. Thesis, University of Bristol.

Calvert, J.R. (2015) Microstructure and Mechanical Properties of WE43 Alloy Produced Via Additive Friction Stir Technology, $\mathrm{PhD}$ diss., Virginia Tech. 
Chamanfar, A., Jahazi, M. and Cormier, J. (2015) 'A review on inertia and linear friction welding of Ni-based superalloys', Metallurgical and Materials Transactions A, Vol. 46, No. 4, pp.1639-1669.

Dalgaard, E.P., Wanjara, J.G., Cao, X. and Jonas, J.J. (2012) 'Linear friction welding of a near- $\beta$ titanium alloy', Acta Mater., Vol. 60, No. 2, pp.770-780.

DoD TRL Definition (2011) Technology Readiness Assessment (TRA) Guidance [online] http://www.acq.osd.mil/chieftechnologist/publications/docs/TRA2011.pdf (accessed 3 October 2016).

Dilip, J.J.S., Janaki Ram, G.D. and Stucker, B.E. (2012) 'Additive manufacturing with friction welding and friction deposition processes', International Journal of Rapid Manufacturing, Vol. 3, No. 1, pp.56-69.

Dilip, J.J.S., Babu, S.S., Rajan, V., Rafi, K.H., Janaki Ram, G.D. and Stucker, B.E. (2013) 'Use of friction surfacing for additive manufacturing', Materials and Manufacturing Processes, Vol. 28, No. 2, pp.189-194.

Deloitte University Press (2014) Global Aerospace and Defense Sector Financial Performance Study, July, pp.1-52 [online] https://www2.deloitte.com/content/dam/Deloitte/global/ Documents/Manufacturing/gx-mfg-2014aandd-global-financial-performance-study.pdf (accessed 20 September 2015).

DOE Report (2015) Report on Additive Manufacturing Technology Assessment, DOE [online] http://energy.gov/sites/prod/files/2015/02/f19/QTR\%20Ch8\%20\%20Additive\%20Manufacturi ng\%20TA\%20Feb-13-2015_0.pdf (accessed 19 September 2015).

Gandra, J., Krohn, H., Miranda, R.M., Vilaça, P., Quintino, L. and dos Santos, J.F. (2014) 'Friction surfacing - a review', Journal of Materials Processing Technology, Vol. 214, No. 5, pp.1062-1093.

Gausemeier, I.J. (2011) Report on Thinking Ahead the Future of Additive Manufacturing - Analysis of Promising Industries, Direct Manufacturing Research Center, pp.1-99 [online] https://dmrc.unipaderborn.de/fileadmin/dmrc/Download/data/DMRC_Studien/DMRC_Study. pdf (accessed 20 September 2015).

Giffi, C.A., Gangula, B. and Illinda, P. (2014) 3D Opportunity for the Automotive Industry, Deloitte University Press, May [online] http://dupress.com/articles/additive-manufacturing-3dopportunity-in-automotive/?coll=8717 (accessed 20 September 2015$)$.

Hiroshi, K., Koji, N., Tsukasa, W. and Kenji, N. (2014) 'Application of linear friction welding technique to aircraft engine parts', IHI Engineering Review, Vol. 47, No. 2, pp.40-43.

Hofmann, D.C., Roberts, S, Otis, R., Kolodziejska, J., Dillon, R.P., Suh, J.O. and Borgonia, J.P. (2014) 'Developing gradient metal alloys through radial deposition additive manufacturing', Scientific Reports, Vol. 4, No. 4, pp.1-8.

Kallee, S.W., Nicholas, E.D. and Russell, M.J. (2003) 'Friction welding of aero engine components', 10th World Conference on Titanium, Hamburg, Germany.

Kandasamy, K., Renaghan, L.E., Calvert, J.R., Creehan, K.D. and Schultz, J.P. (2013a) 'Solid-state additive manufacturing of aluminum and magnesium alloys', MS\&T conf. Proceed.

Kandasamy, K., Renaghan, L.E., Calvert, J.R., Creehan, K.D. and Schultz, J.P. (2013b) 'Additive friction stir deposition of WE43 and AZ91 magnesium alloys: microstructural and mechanical characterization', Advances in Powder Metallurgy and Particulate Materials, Vol. 2, No. 10, pp.111-120.

Koykendall, J., Cotteleer, M., Holdowsky, J. and Mahto, M. (2014) Report on 3D Opportunity in Aerospace and Defense: Additive Manufacturing Takes Flight, Deloitte Series on Additive Manufacturing, pp.1-25 [online] http://www2.deloitte.com/content/dam/Deloitte/nl/ Documents/manufacturing/deloitte-nl-mer-3d-opportunity-aerospace defense.pdf (accessed 19 September 2015).

Lequeu, P.H., Muzzolini, R., Ehrstrom, J.C., Bron, F. and Maziarz, R. (2006) 'Powerpoint presentation on: high performance friction stir welded structures using advanced alloys', Aeromat Conference, Seattle, WA. 
Lyons, B. (2015) Presentation on Additive Manufacturing in Aerospace; Examples and Research Outlook, The Boeing Company, September [online] http://www.naefrontiers.org/File.aspx?id $=31590$ (accessed 20 September 2015).

Mendez, P.F. and Eagar, T.W. (2002) 'New trends in welding in the aeronautic industry', 2nd Conference of New Manufacturing Trends, Bilboa, Spain.

Mishra, R.S. and Ma, Z.Y. (2005) 'Friction stir welding and processing', Materials Science and Engineering: R: Reports, Vol. 50, No. 1, pp.1-78.

Mishra, R.S., De, P.S. and Kumar, N. (2014) Friction Stir Welding and Processing, Springer, Science and Engineering, Switzerland, ISBN: 978-3-319-07042-1.

Palanivel, S., Phalgun, N., Glass, B. and Mishra, R.S. (2015a) 'Friction stir additive manufacturing for high structural performance through microstructural control in an Mg based WE43 alloy', Materials \& Design, January, Vol. 65, pp.934-952.

Palanivel, S., Sidhar, H. and Mishra, R.S. (2015b) 'Friction stir additive manufacturing: route to high structural performance', JOM, Vol. 67, No. 3, pp.616-621.

Threadgill, P.L. and Russell, M.J. (2007) 'Friction welding of near net shape preforms in Ti-6Al-4 V', 11th World Conference on Titanium (JIMIC-5), Kyoto, Japan.

Vairis, A. (1997) High Frequency Linear Friction Welding, PhD diss., University of Bristol.

Vairis, A. and Frost, M. (1998) 'High frequency linear friction welding of a titanium alloy', Wear, Vol. 217, No. 1, pp.117-131.

Vayre, B., Vignat, F. and Villeneuvec, F. (2012) 'Metallic additive manufacturing: state-of-the-art review and prospects', Mechanics \& Industry, Vol. 13, No. 2, pp.89-96.

Wanjara, P. and Jahazi, M. (2005) 'Linear friction welding of Ti-6Al-4V: processing, microstructure, and mechanical-property inter-relationships', Metallurgical and Materials Transactions A, Vol. 36, No. 8, pp.2149-2164.

White, D.R. (2002) Object Consolidation Employing Friction Joining, U.S. Patent \# 6457629.

Wohlers Report (2016) 3D Printing and Additive Manufacturing State of the Industry Annual Worldwide Progress Report, Fort Collins, CO, USA.

Woloszyn, A. and Howse, D. (2001) 'Nd:YAG Laser welding of a stiffened panel demonstration component', 8th NOLAMP Conference, Copenhagen. 